\title{
Features of the Dmanisi mandible
}

THE molar teeth of the jaw show a great size reduction from front to back, greater than that known for any Asian (or African) $H$. erectus fossil or sample, and similar in some ways to that seen in later 'archaic' specimens of $H$. sapiens, such as those from Atapuerca (Spain). The rami are broken away, but they would almost certainly have splayed out postero-inferiorly as in African and Chinese $\boldsymbol{H}$. erectus; moreover, the rear of the tooth row is crowded, as evidenced by the reduced $M_{3}$ and lack of a retromolar space. As in all $H$. erectus, the symphysis in the Dmanisi mandible is rounded anteriorly, although it does not slope back as steeply as in some early African individuals (for example WT 15000; ref. 14). On the other hand, the Dmanisi jaw shows no sign of the lateral tubercles on either side of the symphysis which are responsible for the mental trigone in the earliest 'archaic' $\boldsymbol{H}$. sapiens. These tubercles are probably the result of greater 'wishboning' stress due to increased brachycephaly and klinorhynchy in early $\boldsymbol{H}$. sapiens. The angulation of the mental area is less important than this biomechanical shift, which should be the subject of renewed investigation.

All the mandibular differences may reflect evolution towards a wider cranial base and perhaps other 'gestalt' changes in earliest 'archaic' H. sapiens as compared to $H$. erectus. Increased brachycephaly would result in less prognathism and greater distance across the mandibular condyles, so that the gonial area need not splay out to provide proper position for the masseter muscle, and the symphysis, in effect, would 'migrate' back to the lateral tubercles as it widens. As the anterior dentition later becomes smaller, the intertubercular width decreases and the general gracility leads to the modern trigone and mental eminence.

This new interpretation of the anterior mandible leads to a better understanding of the value of this region in taxonomic eva. luation of individual fossils - for example, the Tighenif (ex-Ternifine) mandibles appear to display lateral tubercles, which led one of us (D.D.) to transfer that popula. tion to $H$. sapiens ${ }^{18}$. In turn, given the estimated age of 0.6-0.7 Myr for Tighenif and the age of $\sim 0.6 \mathrm{Myr}$ for the Bodo (Ethiopia ${ }^{19}$ ) cranium of early H. sapiens, it is likely that, at the least, earliest 'archaic' Homo sapiens populations were present in the northern half of Africa before the earliest known anatomical evidence for their presence in Europe, $0.5 \mathrm{Myr}^{2}$. Recent evidence from East Asia suggests that there was a late but long $(0.3-0.15 \mathrm{Myr})$ period of overlap between 'archaic' $\boldsymbol{H}$. sapiens and late-surviving $\boldsymbol{H}$. erectus. This implies that the routes to East Asia might not have been open to 'archaic' $H$. sapiens until after Europe had been successfully inhabited.

D.D.\& E.D.
Analytical details have not been published for either the date or the palaeomagnetic profile, but they are concordant with a correlation to the Olduvai normal geomagnetic subchron, currently dated between 1.77 and $1.95 \mathrm{Myr}^{6}$; the base of the Pleistocene is defined as just younger than the end of this interval. This would fit closely with the estimated age of the faunal assemblage, which might date at between 2.1 and $1.4 \mathrm{Myr}$. If indeed the polarity is normal, no other option remains: the Réunion Subchron(s) date to $2 \mathrm{Myr}$ or older ${ }^{12}$, while the only younger normal subchrons are the newly revitalized Cobb Mountain at about 1.15-1.2 $\mathrm{Myr}^{13}$ and the Jaramillo spanning $1.0 \mathrm{Myr}$. The associated fossil mammals, including rodents of Pliocene affinity and no species of Biharian age, count as strong evidence against the younger dates. On the other hand, it is conceivable that the palaeomagnetic analysis did not involve sufficient (alternating field) demagnetization to remove later overprinting, in which case the fossils could be of somewhat younger age.

There is little doubt that the mandible itself can be attributed to Homo erectus. We do not consider that the African Pleistocene fossils sometimes termed $H$. ergaster represent a distinct biological species, given the known ranges of variation - ref. 7 supports the concept of $H$. ergaster, while refs 14 and 15 reject it (as we do). But several features of the Dmanisi jaw are quite distinctive, especially when taken in combination. The technical details and their implications are discussed in the boxed text.

As Gabunia and Vekua note, if the Dmanisi specimen indeed dates to 2.0-1.5 Myr, roughly 1 Myr passed between then and the first widespread occurrence of humans farther west, in Europe proper. Was this time gap the result of climatic severity, such that pre-sapiens humans were unable to survive long in the periglacial environments of even southern Europe? Or was it related to their inability to cope with the large terrestrial carnivores, as hypothesized by Turner ${ }^{16}$ ? Further studies of the archaeological residues at Dmanisi, as well as determination of whether the fauna was human food refuse or the result of other taphonomic circumstances, should help to answer these questions. As Bar-Yosef ${ }^{17}$ points out, most of the mammalian fauna of Pleistocene southwest Asia is derived from farther east or perhaps Europe; little of it, other than Homo, comes from Africa. Whatever the sequence of sites, $H$. erectus must have traversed southwest Asia en route to Indonesia, China and the rest of Eurasia, but various attempts may have been made before one or more colonizations were successful ${ }^{17}$.

Perhaps the situation in the Early Pleistocene was analogous to that around 0.1 Myr, when (according to one view) early modern humans entered southwest Asia from Africa but did not move into Europe for over 50,000 years. It may be that (1994)

2. Roebroeks, W. \& van Kolfschoten, T. Antiquity 68 , 489-523(1994).

3. Gabunia, L. \& Vekua, A. Nature 373, 509-512 (1995)

4. Swisher, C. C. et al. Science 263, 1118-1121 (1994).

5. DeVos, J. \& Sondaar, P. Science 266, 1726-1727 (1994)

6. Swisher, C. C. Science 266, 1727 (1994).

7. Wood, B. A. Courier Forschungs-institut Senckenberg 171, 159-165 (1994)

8. Rightmire, G.P. The Evolution of Homo erectus (Cambridge Univ. Press, 1990)

9. Bonifay, E. \& Vandermeersch, B. (eds) Les Premiers Européens (Comité Travaux Historiques Scientifiques, Paris, 1991)

10. Asfaw, B. et al. Nature 360, 732-735 (1992) cultural adaptation, involving toolkit technology and perhaps broader social evolution, was at the root of both successful invasions of western Eurasia, by 'archaic' and anatomically modern Homo sapiens, respectively. Given our growing understanding of Homo erectus and 'archaic' Homo sapiens palaeodemography and migration patterns, it is becoming ever more clear that these two species form an ancestor-descendant pair in the Middle Pleistocene, with the latter replacing the former from west to east. We are now faced with the continued challenge of finding not only more evidence of these extinct populations, but also the palaeoclimatic and perhaps technological conditions which allowed or prevented them from occupying various regions of the Old World, including the cul-de-sac we know as Europe.

David Dean is in the Department of Anatomy, Case Western Reserve University, Cleveland, Ohio 44106-4905, USA. Eric Delson is in the Department of Anthropology, Lehman College, and the Graduate School, City University of New York, Bronx, New York 10468, USA, and at the American Museum of Natural History.

11. Verosub, K. L. \& Tchernov, E. in Les Premiers Européens (eds Bonifay, E. \& Vandermeersch, B.) 237-242 (Comité Travaux Historiques Scientifiques, Paris, 1991)

12. McDougall, I., Brown, F. H., Cerling, T. E. \& Hillihouse, J. W. Geophys. Res. Lett. 19, $2349-2352$ (1992).

13. Renne, P. R. et al. Geology 22, 783-786 (1994).

14. Walker A \& Leakey, R. (eds) The Nariokotome Homo erectus Skeleton (Harvard Univ. Press, Cambridge, MA. 1993).

15. Braüer, G. CourierForschungs-Institut Senckenberg 171, 301-318 (1994).

16. Turner, A. Courier Forschungs-Institut Senckenberg 171, 241-247 (1994)

17. Bar-Yosef, $O$ in Origins of Anatomically Modern Humans (eds Nitecki, M. H. \& Nitecki, D.) 23-66 (Plenum, New York, 1994).

18. Dean, D. thesis (City Univ. New York, 1993)

19. Clark, J. D. et al. Science 264, 1907-1910 (1994). 